\title{
'What we talk about when we talk about culture': Frans de Waal on science, morality and the primatology of the human animal
}

\section{Helena Feder}

To cite this article: Helena Feder (2017) 'What we talk about when we talk about culture': Frans de Waal on science, morality and the primatology of the human animal, Green Letters, 21:2, 199-212, DOI: $10.1080 / 14688417.2016 .1250225$

To link to this article: https://doi.org/10.1080/14688417.2016.1250225

曲 Published online: 03 Nov 2016.

Submit your article to this journal $๘$

III Article views: 296

Q View related articles $\sqsubset$

View Crossmark data $־$ 


\section{'What we talk about when we talk about culture': Frans de Waal on science, morality and the primatology of the human animal}

Helena Feder

Hailed by Time in 2007 as one of 'the World's One Hundred Most Influential People' and by Discover in 2011 as one of 'the 47 (all time) Great Minds of Science', Dr Frans B. M. de Waal is the C. H. Candler Professor of Primate Behavior at Emory University and Director of the Living Links Center at the Yerkes National Primate Research Center. de Waal received his Ph.D. in Biology and Zoology from Utrecht University, in the Netherlands, in 1977, and has published numerous articles on primate cognition and behaviour in various journals, including Science, Current Biology and the Proceedings of the National Academy of Sciences, and won a staggering number of awards. He has also published 10 popular books based on his scientific work, including Peacemaking among the Primates (for which he won the Los Angeles Times Book Award in 1989) and, most recently, The Age of Empathy: Nature's Lessons for a Kinder Society (2009), The Primate Mind: Built to Connect with Other Minds (with P. F. Ferrari, 2012), and The Bonobo and the Atheist: In Search of Humanism among the Primates (2013).

Writing on nonhuman animal cultures in The Ape and the Sushi Master: Reflections of a Primatologist (2001), de Waal exclaimed, "one cannot escape the impression that it is an idea whose time has come". Surveying and theorising the growing field of animal cultural research, termed 'cultural biology', he argued, 'The standard notion of humanity as the only form of life to have made the step from the natural to the cultural realm - as if one day we opened a door to a brand-new life - is in urgent need of correction ... The idea that we are the only species whose survival depends on culture is false, and the entire juxtaposing of nature and culture rests on a giant misunderstanding'. In Good Natured: The Origins of Right and Wrong in Humans and Other Animals (1996), Primates and Philosophers: How Morality Evolved (2006) and the recent The Bonobo and the Atheist, de Waal examines the way in which morality, thought by many the defining characteristic of humanity, derives from a capacity shared with a great many other animals. Evolved Morality: The Biology and Philosophy of Human Conscience (2014), edited with Patricia Smith Churchland, Telmo Pievani and Stefano Parmigiani, continues this research, bringing us 'back to the original Darwinian position that moral behavior is continuous with the social behavior of animals, and most likely evolved to enhance the cooperativeness of society', transforming 'cherished views on if and why we are the only moral species'. ${ }^{1}$

Feder: It is fair to say your work on primates has, after that of Kinji Imanishi, pioneered the field of cultural biology. You've had a tremendous impact on 
primatology and biology, and on popular culture as well. In part as a result of such work, some scientists have been experimenting with less anthropocentric methods of inquiry. What do you think of Participatory Action Research, such as the recent work at the Great Ape Trust in lowa? Gay Bradshaw positions PAR as a kind of trans-species science, in which apes participate in formulating questions for investigation.

de Waal: Yes, I'm a bit sceptical about the whole language ape field. I think there was some rigorous science in that field, mainly work by Sue Savage-Rumbaugh.

Feder: What do you consider rigorous?

de Waal: Rigorous in the sense that they had controlled procedures and they didn't feed the animals information. That they were critical of what they found. So, for example, Washoe said 'water birds' (you know, the famous example), but I want to know more about Washoe's other expressions. Was this just a fluke, or was this systematic in Washoe? That's an important question for scientists.

There have been a number of overblown statements and conclusions in ape studies recently. So, for example, Koko recently 'felt sad' because Robin Williams died, but it's so unlikely that Koko can grasp the death of someone that she only met once thirteen years ago. It's more likely a human projection than anything else, or maybe Koko was sad because everyone else around her was sad. That I can understand, but grasping the death of someone that she cannot even see dead? I think apes have a strong response to the death of individuals that they know and can see.

I've become quite sceptical about that whole field because I think it's in decline. It's now making overstatements in a bid for attention. So I'm reluctant to believe everything I hear.

Feder: Have you seen the Koko blog, maintained by The Gorilla Foundation (www. koko.org)?

de Waal: Of course! She's not maintaining that. Someone else is maintaining that. When Koko was said to be sad about Robin Williams, all we saw was a picture of Koko sitting there with her head down - which could have been taken any time. I don't know what it means.

Feder: Are there currently any experiments with human-language apes at Yerkes?

de Waal: The Kanzi experiments started at Yerkes. At that time the symbol language used was called 'Yerkish'. So, these started here, but no one is doing this work anymore.

Feder: To shift fields within primatology, what do you think of Robert Sapolsky's baboon troop M4? Following the deaths of all the high-ranking males (chronicled in A Primate's Memoir), the troop underwent, as Sapolsky puts it, 'a cultural change', from a typically patriarchal, aggressive culture to a more sociallyaffiliative, matriarchal culture.

de Waal: I find it very interesting because there are very few examples of social culture in animals. We do a lot of work on gestural differences, tool use differences, animal-environment-interaction-type differences, and that's usually what we talk about when we talk about culture. There are only two examples of social culture that I know of. One is Robert Sapolsky's baboon troop, and the other is a study that we did on juvenile macaques learning reconciliation skills from each other. Robert's example is very striking in that, ten years later, the troop is still different, which is very hard to explain because there's so much male exchange between wild baboon troops. And there was male migration into that troop. 
He thinks that it's the females who have maintained their levels of peacefulness culturally and that's not excluded. I'm not sure that he has proven it, and I'm not sure that he himself thinks that he has proven that that's how it operates, but it's a possibility. It is true that it is hard to explain it in a different way. You could say, for example, of course it is logical that if the most aggressive males of the troop are removed that the troop will become more peaceful. That part is not hard to understand. The part that is hard to understand is why, ten years later, it is still so peaceful. For that we need to have an explanation.

Feder: Sapolsky suggested that when the new males come into the troop, members acculturate them. Within a few months, these young males learn the more peaceful ways of the troop.

de Waal: I think it's entirely possible. I've seen macaque troops, like rhesus monkeys, who are pretty aggressive, like baboons. But I've also seen troops that had high levels of tolerance in captivity. I wonder how those were established. I find social cultures very interesting, because we usually talk about the tool-use cultures, eating habits or things like that.

Feder: Such as potato washing.

de Waal: Right. I think it's a good example.

Feder: Could I go back, then, to Koshima and the potato washing first observed by Satsue Mito in 1953? Decades later, you visited the island and saw monkeys dipping potatoes in the ocean, rather than a stream, referred to as 'seasoning'. Do you still feel that this is a clear example of social learning?

de Waal: Yes, I think it is a good example. It was questioned at some point by a Canadian psychologist, Bennett Galef. He didn't think it was culturally transmitted, but I think he got many things wrong, in part because he didn't visit the place and didn't talk to the scientists. But, generally, it's a human-induced tradition that is socially [conspecifically] transmitted. Now we just call that a 'tradition', and use the word culture if animals show a range of traditions. I think the term culture has, in primatology at least, become much more accepted than it used to be. Outside of primatology I'm not sure that everyone is ready for it.

Feder: Koshima brings me to another question. When William McGrew reviewed Good Natured in Scientific American he seemed to question if nonhuman cultures can be studied in a laboratory. Koshima Island blurs the line between field and laboratory (and so between field and laboratory research). McGrew's point was that chimpanzees in the wild are less socially inclined than they are in the laboratory. What do you think about this?

de Waal: Bill is a field worker, but I think he recognises by now that we need some captive work to solve certain problems. Field workers and captive workers have always been sort of head-to-head.

You know, it used to be that fieldwork was considered non-science and captive work was the 'real' science. Then in the 60's and the 70's, we heard the opposite. People said, 'Field work is the real science because that's where animals live and that's where they evolved'. And now we're back, at least in the culture debate, to a lot of captive studies and controlled experiments to investigate some areas of social learning. I think Bill recognises that some issues cannot be resolved in the field. You find that chimpanzees in the wild crack nuts with stones, for example, but you don't know how they learned it or if they can learn these things from each other. I'm not sure that these questions are easily answered in the field.

You need captive studies to setup the kind of experiments that we did. For example, we setup experiments where one chimp can do something and another 
chimp can watch, and we can see if they learned from each other. One approach, lab or field work, isn't superior to the other; both sort of fit together to get at the question of animal culture.

Nowadays, of course, field work has changed. Scientists sometimes do experiments in the wild, though these are limited. And they come back with all sorts of samples (such as faecal, urine and blood samples) to analyse all sorts of things (DNA, gene expression, hormone levels ...). For all of this, they need lab analysis. And then, for cognitive questions, we need captive studies. It's a bit like looking at a schoolyard full of children. Looking at human children play, you would never guess that they are smart. You just see them running around screaming. It is the same with chimps in the field. Yes, you can see glimpses of their intelligence because you see them cracking nuts with stones and stuff like that. So you say, 'Hey, they must be smart'. But to really know how smart they are you can't just do field observations. Just like with kids, you need to bring them into a room, put them behind a desk, and ask them questions or present them with a problem. Just observing them in the field is not sufficient; you need to give them a task to accomplish. This is why we need collaborative research between field and captive workers.

Feder: What about the kind of field research pioneered by Dian Fossey? She is not every primatologist's favourite example, but she acculturated herself to the gorillas she studied and, because of this, had more insight into their behaviour.

de Waal: Yeah, sure! The thing is how do you convince others? I can be a fieldworker and in tune with my animals, even understand them almost as a participant [in their culture]. But then you come out of the forest and you go to a group of hardnosed scientists ... Maybe the general public will buy into it, but hardnosed scientists are going to ask difficult questions. They are going to say, 'How do you know that they have empathy?' 'How do you know that they care about their status in the group?' 'What do you know about that?' You cannot simply ask these animals, 'Do you care about your status?' You make deductions from their behaviour. That's where the problem arises, because in science we like to have answers that can be verified.

Of course, it's very helpful to be empathic with your animals. Long ago, Imanishi advocated empathy, and Konrad Lorenz emphasised empathy as a technique. I do think it is important, but it's not sufficient; that's the problem.

Feder: What about other scientific intangibles? Your books treat anecdotal knowledge as valuable. What about intuition? You've written, for example, that anthropomorphism (animalcentric anthropomorphism) ought to be taken seriously given that it applies intuitions about ourselves to creatures who are very like us.

de Waal: I look at it as a first step most of the time; I don't think it's sufficient. The term anthropomorphism has been overused, especially by the behaviourists (followers of B.F. Skinner) who wanted to keep us away from studying animal mentality. But if you have animals that are close to us, such as a chimpanzee or a bonobo, then anthropomorphism should in fact be the default assumption. The default assumption should be, if they do something similar to us, under similar circumstances, then it must be similarly motivated and mentally similar. Whatever we call it for ourselves, we should use that terminology for them. Obviously, I'm not against anthropomorphism in the case of apes or other mammals, overall. But when you get to other species, like insects or invertebrates or fish for that matter, you have to be careful.

I use intuition and anthropomorphism and anecdotes to hypothesise. I can use all of that to get at a question but I still have an obligation to collect information to make a harder case. Scientists do have disdain for anecdotes, but anecdotes can be 
awfully interesting. I think every big research question has started with a few anecdotes, a few observations about which people have said, 'Hey, you think this could be going on?' And that's how we get into the big questions.

Feder: Is this where the 'two cultures' of the sciences and humanities meet? Asking questions and telling stories both rely heavily on curiosity and intuition.

de Waal: The thing is that people fall for stories much more easily than for evidence. For example, today I will give a lecture and show my famous video of the cucumber-throwing capuchin monkey. I can show the data ten times to people and say, 'This was significant and this was significant'. Produce bar graphs, and so on. I can show these ten times to people, but the video is more convincing to them, and it is just one minute of animal behaviour. I find it frustrating sometimes, because if people were really critical thinkers they would say, 'Well that's just a video. They could have edited it; maybe it happened just once'. Data is absolutely needed to convince a sceptic, but the data alone rarely convinces a general audience.

Feder: Well, it is a video shown by an expert, and Americans (to speak to the case at hand) have faith in experts, albeit a highly schizophrenic one. And, of course, we're an ocularcentric species; seeing things is more convincing to us.

de Waal: Also the behaviour of the monkey is very emotional, so I think that connects with humans. The data is, of course, non-emotional. The data is just P-value whatever. [De Waal laughs]

Feder: In contrast, in The Bonobo and the Atheist, you use Hieronymus Bosch's work as a frame for an assessment of the tension between religion and morality. This opens a question you didn't address in the book, the old question of the relationship between art and morality. Do you have any thoughts on this?

de Waal: Bosch is considered a moralising painter, and often when people say he is a 'moralising painter' what they mean is that he translated Christian morality into his paintings - such as, you'll go to hell if you do the wrong things, etc.

But I think he was much more modern than that. He was a subversive painter in that he questioned some of the church's power. I sometimes wonder how he got away with it because the Spanish came to occupy that part of the world. The Spanish Inquisition was not particularly nice. The Spanish must have been enthralled by his paintings because so many of them ended up in Spain. It's a puzzle, and if you read the literature on Bosch you see that people are still puzzled about this. Why was he so popular during a time in which heretical ideas were persecuted? Superficially, his work looks like Christian morality, but you can feel that there are other things going on.

Feder: Could I press you a bit on the question of art and morality? As you have it, morality is like empathy; it is older than religion. It's not a veneer; it's essential to who we are. What about art? Perspective taking is, of course, also central to art.

de Waal: I was recently in a cave in the south of France. It was called Niaux, with 40,000 year-old cave paintings. I still distinctly remember we saw animals but not bears and lions, not the predators. The guide said that these paintings were probably based on certain stories. That's why they contained such a small selection of animals. There were many more animals in the area, but these paintings always focused on the same characters, animals that were needed for food and so on.

The guide told us that he felt these animals probably played a role in the stories that these people told each other at night around the campfire. There are some very interesting studies now about the role of campfire in promoting narration. Polly Wiessner at the University of Utah, for example, systematically looked at what 
people talk about in the daytime and at night. When people sit around a fire they talk differently.

Feder: Does it seem logical to assume that religion was one of the many kinds of stories that evolved out of making art?

de Waal: Yes. Religion is also based on imagination. God isn't something that exists or doesn't exist; it's something that we imagine or don't imagine. That's how I see it. If imagination is at the root of religion, then of course that's also the case with art.

Feder: What about nonhuman aesthetics? I don't mean 'staged' paintings (in which people set up paints and brushes and ask apes or elephants to make art), but true aesthetic preferences in nonhuman creatures.

de Waal: There are studies that started with Desmond Morris's book, The Biology of Art. I think that's where we got started on that topic. And then, of course, it became confused with the question 'Can apes paint?' Yes, it would be very strange if preferences for certain colour patterns and symmetries were unique to us. You mentioned Koko before. Koko, it is claimed, has produced figurative art, but I couldn't recognise that in her paintings. The claim seems more a product of human imagination. Apes, as far as I know, don't produce figurative art. I think that probably requires a symbolism that they don't have. But they do have a certain aesthetic sense, I believe.

Feder: In The Bonobo and the Atheist, you also discuss the tension between loyalty and morality, which, I think, could be a very useful way to consider certain ecological problems.

de Waal: Loyalty and morality came up again in my last book because I talked about utilitarianism. Utilitarianism has very serious limitations. For example, Sam Harris argues it is moral to do what's best for the greater good of our species. The more people you help, and the less people you hurt, the more moral the action. But this formula doesn't have any interpersonal connections integrated into it. It's such an abstract formulation that I have great trouble seeing it as a moral principle we can go by. That's also my problem with Peter Singer. I think Utilitarianism is a very limited and an un-biological way of thinking about morality.

Feder: What of the larger tensions between ecological and biological approaches to morality? Ecology tends to think in terms of the greatest good for the greatest number of species or systems, while biology tends to focus on individual species or groups of species.

de Waal: Yes, the thing is that we always need to pull it back to ourselves. It's a bit like the question asked in evolutionary biology: 'Is there any trait that is good for the species?' We usually answer, 'No. Animals don't care about their species. They care about themselves and their kin and their group, maybe - but not about their species'. This would be my same answer. Probably the most convincing ecological argument you could make to me about my behaviour would be something that relates to me. That's usually the tactic we take anyway. We know that people are not interested in the larger ecology independent of themselves.

Feder: In Good Natured you likened the question of morals in other species to questions about culture and politics, and language and intelligence, and so on. These questions form a constellation, but do they have a core? Is there one question about the continuity of species around which all these other questions revolve? 
de Waal: Well, at an intuitive level, people have always understood that we're animals - even if religions tell us that we have souls and animals don't have souls. Certainly if you look at young children, young children don't distinguish very clearly between themselves and other animals. At some point we're indoctrinated; this must happen at adolescence. At some point we're told that we are different from animals, that we are not really animals. About half of people believe this. You still meet many people for whom the last thing they would do is compare themselves to animals. Their identity as human means being different from other species.

Feder: As you've written, many scientists keep shifting the lines to keep the 'hairy apes' on the other side of consideration. Have you read David Livingstone Smith's Less Than Human?

de Waal: I know him from Facebook. [De Waal laughs]

Feder: He takes Erik Erikson's idea of pseudospeciation a little further, arguing that human beings are 'natural-born essentialisers', that we have an innate tendency to treat other humans that are not part of our group as another species. The question I'm circling is do you think the human animal has a fundamental problem with difference, a low tolerance for difference?

de Waal: Yeah, I think in the West we set ourselves apart from the animal kingdom and, of course, some people claim that there's even a moral component to it, in the sense that when we started exploiting animals, as farmers, we needed to that. Farmers control animals and kill them in the end. Instead, the hunter has quite a bit of respect for the animal.

Our whole culture draws a line between ourselves and other animals. My agenda, to a large degree, is of course to break down this barrier by saying, 'Well it's just a product of our imagination" or "It's a product of our culture and religion'. In scientific terms, it doesn't exist to the degree that we think it exists. Of course, trying to play down that line has ethical implications. All around us people are beginning to draw the conclusion that either we should or shouldn't eat animals, that we should treat animals differently.

Feder: In his later work Jacques Derrida argued that while humans are animals, animals are not 'animals'. The idea of the animal is a construction to bolster human exceptionalism. 'Animals' aren't mindless bodies and human beings aren't the subjects of reason that Humanism tells us we are. For example, new studies tell us we actually make 'rational' decisions very quickly and rationalise them after the fact. However, in your most recent book you argue that bonobos have empathy but not morality because morality is, as you put it, 'a logically coherent system'.

de Waal: I have this type of discussion with anthropologists who tell me, 'I lived with people who are clearly moral but have no moral codes'. They don't strive for justification; they don't strive for logic; they don't strive for any of that.

This is probably a Western thing because these anthropologists tell me, 'If I ask these people "why is this moral and not that" they say that it has always been like that'. That's their answer: 'It has always been like that'. They're not looking for justification or trying to argue for or against a position. In the West we think that's the core of morality, but it really may not be.

Feder: Yes. Small children are moral, but they don't usually or necessarily have a logically coherent system. As you point out, such a system often makes being moral more difficult, because in such systems morality is bent towards universal principles and not the immediacy of life. 
de Waal: Yes. I recently wrote a paper on normativity, called 'Natural Normativity'. This paper gets into this question because, of course, the first argument that every philosopher uses against a naturalised morality is the 'is-ought question'. Can we move from facts to values, basically. The paper in Behaviour, an ethological journal, states that there's a lot of normativity in animal behaviour. If we look at it this way then maybe the jump from 'is' to 'ought' is not as big.

I think that the jump seems very big at the conceptual level. If I describe, let's say, how rabbits behave and I conclude how rabbits 'ought' to behave, that's going to be a very difficult conceptual issue. But if rabbits have normativity in their behaviour, which I bet they do, then the jump is not as big. That's the sort of argument that I'm following. Of course many philosophers will disagree with this. They always look at this problem at the conceptual level because that's where they operate.

Feder: Is this why you and others, such as E.O. Wilson, have said that ethics should be temporarily taken out of the hands of philosophy, because abstraction isn't a good place from which to consider another's needs?

de Waal: Yeah. And so they are under stress, of course. Philosophers know this, that science does not always support their approach.

Feder: The whole idea of stretching for logical coherence seems, as you suggest, a cultural phenomenon, but when we talk about Western culture we're talking about global capitalism. Capitalism compartmentalises things routinely; it has cordoned off the work of ethics, the costs and consequences of all the decisions that impact so many human and nonhuman lives (whether it's underpaid labour, the meat industry, etc.), to religion and philosophy, where it does not need to pay attention to the results.

de Waal: Let me say a few things about this. There are some interesting studies by Robert Frank, the economist, on students of economics departments and business schools. Either most of the 'soft' students, so to speak, drop out, or these students become more selfish over time. Playing cooperative games with them, games in which you can either choose to cooperate or to make selfish decisions, you see that third or fourth year students have become far more selfish than students of other disciplines; whereas, in their first year, they are still more similar to other students. Frank interprets this as a process of indoctrination. Basically, they learn in class that the whole world operates on selfishness and then translate this view into behaviour. They cannot even imagine that the world could function in any different way.

And so, yes, the business world has this perspective. And that's also why when there's a big scandal, such as the Enron scandal, they pay attention to ethics for a couple of years and then it disappears again. They go right back to their regular mode of behaviour. Ethics is only a second thought. Money is the big thought and ethics is the small thought.

Feder: There have been several articles on the high incidence of sociopathology in CEOs, and in those in business generally (estimated by some to be four to ten times greater than in the general population), but this tendency permeates our entire culture. Americans, for example, make a lot of antisocial choices. Even if we broaden those responsible for the work of ethics to the academy generally, the whole question of morality is still pushed into the smaller corners of American culture, economically speaking.

de Waal: There is an interesting thing about American capitalism. There are some people who misuse their money, like the Koch brothers, but there are other people who are philanthropic. Philanthropy is big in this country. Once you have a lot of 
money to dispense, you start doing good things with it. That's not a tradition in Europe. I noticed this difference because if you go to a zoo in the U.S., for example, it is sponsored by lots of people or corporations. If you go to zoos in Europe, they are not getting money from anyone except the government. It is an interesting aspect of American capitalism. I share all your cynicism about it. It's completely driven by selfishness and greed, but in the end, the guys who have all the money can also use it for good purposes, and they sometimes do.

Feder: Altruism is as natural as anything else. But, in many cases, if these people were truly altruistic, would they be rich in the first place?

de Waal: I understand that, but it's a silver lining. It's a silver lining of the American capitalist system.

Feder: What are you working on right now? What is your next book going to be about?

de Waal: I'm writing a book on animal intelligence ... and not just on primates. A lot of the cognitive studies on animals started with primates, and then rippled to crows, dogs and elephants. They have rippled in all sorts of directions, and I find that whole convergent evolution thing very interesting.

The book considers how we humans tackle the problem of animal intelligence. It's not just about other animals, it's also about human attitudes and ingenuity, and the whole struggle of the last century to even talk about animal cognition. It seems strange, because everyone talks about it now, but it was different in the 1980s, or when Donald Griffin wrote his book in the 1970s. Back then people would ask, 'Do animals even have minds?' So, the book is in part about anthropocentrism, because everything else that other animals do needs to be compared to what we do - even when it's not always comparable, like echolocation.

Feder: How does the book discuss difference?

de Waal: I look at the human-uniqueness question as an intellectual dead-end, but many psychologists still focus on this. If I talk about animal intelligence the first question that comes up is, 'But how are we then different?' ... as if that's a central question.

Feder: It's often an anthropocentric question.

de Waal: Yes, because, for example, in medicine or general biology we would never ask, 'What is special about the human liver? How is the human liver different from the rat liver?' No one considers that an interesting question. The interesting questions are, 'What does the liver do?' and 'What is it good for?' and 'How does it function?' Those are the interesting questions. And if the human liver is a bit different from a rat liver, which I'm sure it is, that's a secondary question.

But when it comes to cognition, we always go straight for the human difference, which I think is a dead-end because it leads to claims of 'We can do this' and 'We can do that'. All these claims fall apart at some point. It's part of the problem if you study elephants, for example. We as humans need to start thinking, 'Okay. You're not working with your hands; you're working with your trunk'. Or, 'You're not working with your vision; you're working with your smell'. That's why the discovery of echolocation was such a big deal, because it doesn't relate to anything we did. All that people knew at the time is that bats can move about in a dark room where they cannot see a thing. They can even catch prey in a dark room! Scientists talked about it as a sixth sense, which it actually is. It was such a big discovery because we had to think outside of the box of human senses. 
Feder: Yes, this work seems to require huge imaginative leaps. Is this a place where the humanities have something to offer the sciences?

de Waal: I think the humanities help us reflect on things in a way that we scientists usually don't. They help us formulate questions in a different way. It is true that, at the moment, philosophy is a bit left behind. The philosophers who are not interested in science, are sort of left behind and I think they are going to die off at some point. [De Waal laughs]. It used to be, of course, that philosophy and science were totally intertwined. Look at someone like Goethe; he was an author, a philosopher and a scientist all at the same time.

Feder: As you've suggested before, we should find another word for humanism. But what we in the humanities have come up with, posthumanism, is still quite messy. There are two main branches of posthumanist thought. 'Critical posthumanism' critiques of problems of humanism; it doesn't throw the baby out with the bathwater, but sees human exceptionalism as a problem. Then there's uncritical posthumanism, the 'transhumanist' fantasy of becoming disembodied, downloaded information.

de Waal: The posthumanism that says that we need a philosophy of mind, so to speak, one that is not focused necessarily on our species alone, that includes the much broader context that we are a part of, I completely sympathise with that. The only criticism that I have of that movement is that these scholars don't usually work with animals at all. They're interested in representations of animals. They will write papers on the attitude towards cattle in medieval Japan or something like that. I always feel that if you want to talk about the human-animal connection, human-animal similarity and difference, you should work with other animals. You should get your hands dirty, basically.

Let's say you write about the ethics of animal agriculture. I feel that you need to work for two years on a hog farm, or something like that. I may be very oldfashioned, but I think that would give you a level of insight that you'd never get from books. For example, if you're writing about keeping primates at a primate centre, go work at a primate centre for two years - not as an infiltrator or with any agenda, but just to see what it is like on a daily basis. To see the pros and cons. At zoos and primate centres, there are a lot of dedicated people who love their animals but to work there they have to accept the conditions in which they are being kept. Some of the higher-level administrators could, of course, potentially change things. That is a side of animal keeping that you should see, just how much human care goes into these facilities.

I have a Facebook page, which is very popular at the moment. I often put pictures of animals on it. Half the pictures, I think, come from captivity, and the other half from the field. Now if there's a captive gorilla that I show as a new baby or whatever, there's always a comment such as, 'Why is this gorilla in captivity?' And there's always a zookeeper who replies, 'Well, this is Susie who lives at my zoo'. I see that whole discussion play out. Zoos attract a lot of people who love animals, and take very good care of them under the circumstances.

Feder: Frankly, personally ...

de Waal: You do not approve of zoos.

Feder: Zoos exist largely for human pleasure, and I can honestly say that I do not derive pleasure from seeing animals in cages.

de Waal: They're not only there for pleasure. Initially, of course, they were there for information and pleasure. And the pleasure part has stayed. 
Feder: Animals ended up there, in part, as the spoils of empire. Explorers, naturalists and the like travelled all over the world and brought back cultural products and animals ... and of course some humans were once displayed in zoos too.

de Waal: But they have an educational side.

Feder: Perhaps, but in the Digital Age, do we need to hold animals in cages for educational purposes? Leaving the question of research off the table, I don't think we need zoos for education. Having said that, some animals are now so endangered that zoos may seem their only hope for survival, and I struggle with this.

de Waal: I still feel that seeing the real animals, smelling them and hearing them is a different experience than the one you get on your computer.

Feder: Oh, I agree. But is that a sufficient reason to keep living, sentient creatures in cages or enclosures?

de Waal: The way you keep them makes a difference. The old-fashioned way of keeping animals at the zoo was in small cages. The Paris zoo, which is one of the first, has changed all their tiger cages to birdcages. And so now, where there used to be one or two tigers, there are a lot of small birds. You could see how inappropriate it was to put a tiger in there.

Feder: Doesn't it still seem wrong to keep animals, evolved to fly boundlessly, in cages? As wonderful as it is to see and smell other animals, some animals suffer from stress and post-traumatic stress disorder in zoo conditions, however improved.

de Waal: Yeah, that relates to space and maybe how they were acquired.

Feder: But that's part of it. Part of maintaining zoos is the acquisition of animals, and they're often obtained in pretty horrible ways, right?

de Waal: Yes, and for some animals you can question whether they should even be at zoos regardless of how much space you can give them.

Feder: So then you have to ask yourself, 'Are they necessary?' There are compelling arguments for keeping animals to fight pandemics. But in zoos?

de Waal: Basically every time you use medication you use animal research.

Feder: Yes, that's something one can make an argument for, but zoos aren't necessary.

de Waal: Well, for urban people who don't know anything about nature I think that it's useful to physically encounter animals.

Feder: If the goal is to make these people more ecologically responsible, to make them more sensitive to nonhuman forms of life, then zoos seem even more problematic. If only it were sustainable to ship urban dwellers to the 'exotic' animals!

de Waal: Of course, that's unrealistic. You can say, 'Yes, you can see the elephant in Africa'. But who has the money to do that? It's a very small portion of the people. I think zoos have a very important educational mission.

Feder: They haven't stopped people from treating animals very badly; they haven't stopped the meat industry from turning into a form of Holocaust.

de Waal: If you close all the zoos, then you couldn't see exotic animals first hand, unless you have the money for travel. And that's going to be ten percent of the people .... 
Feder: It's a price many would be willing to pay for knowing that these animals have better lives.

de Waal: I'm not sure that they'd have better lives. You think African elephants have good lives?

Feder: No, not for some time now. As I said, this point is one to struggle with. Gay Bradshaw's Elephants on the Edge presents a useful discussion of African elephants' resistance to colonisation, the way wild elephants (much like humans) resist various forms of colonisation.

de Waal: Animals in the wild don't have such great lives. That's an illusion. The longevity of an animal is a good indication of its health and condition. There are species that don't live very long in captivity, and this was true for the elephant. I'm not sure it's still true. It was true for elephants; it was true for killer whales. And so there are certain species that live shorter lives in captivity. And in those cases you could argue that maybe captivity doesn't suit them unless we change it. Maybe it's not possible for killer whales, for example. But there are many animals, like chimpanzees, who live ten to fifteen years longer in captivity. Captivity is not something that hurts them, necessarily. You may think it hurts them because you are human and imagine, 'If I were sitting in that cage I would be unhappy'.

Feder: Yes, but we both agree that the empathy that leads to this thought, that leads me to make this ethical judgment, is a co-evolved capacity that in many, if not most, cases I share with the very creatures I'm looking at in cages. From this perspective, the main educational function of zoos is as a training ground for ignoring empathy.

de Waal: I've seen many animals in captivity in miserable circumstances, and I would not approve those. But I've also seen many animals in captivity who live social lives in a large spaces.

Feder: There's certainly a spectrum of what captivity looks like, but I don't agree with you on longevity. We could live longer if we gave up all kinds of things humans seem to find important, certain behaviours and experiences, but at what cost? Longevity isn't the measure of a good life.

de Waal: No, I'm not saying that. I think if they live a shorter life in captivity than in the field then you would have an argument. You would have an argument that maybe captivity doesn't suit them. I think animals in captivity, kept in the right way ...

Feder: Could we trust any capitalist system to keep animals the 'right way' given that human beings are treated so badly?

de Waal: Yes, but zoos have improved dramatically over time. The good zoos, at least, have improved dramatically. There are lots of little zoos that shouldn't exist.

Feder: Not to mention circuses and the other horrors out there.

de Waal: Circuses I don't approve of at all, but those kind of experiences were, for me, very important because I loved animals. The exotic animals you never got to see otherwise. Another strategy to improve zoos would be to get involved with the zoo, be part of the zoological society. But it is an illusion that animals in the wild have good lives. That's not a guarantee.

Feder: Wouldn't the better thing to do be to close zoos and put all of our energy into improving conditions in the wild, into protecting wild spaces, because not all animals can coexist with human beings? Grizzly bears and human beings don't work well together. You know, there are just some spaces where human beings 
shouldn't be. Maybe that's what we ought to be doing with our political energy instead of improving zoos.

de Waal: Yeah, the zoos spend an extraordinary amount of money on the enclosures that they built.

Feder: Let's talk about money, because that is a good way into the larger condition of animals in captivity. There are some animals in zoos and in laboratories, but there are far, far more animals raised and processed in the meat industry.

de Waal: The meat industry is much bigger. My dream is that one day we are raising meat in petri dishes. Our desire for meat would still be satisfied, but we wouldn't be hurting anybody.

Feder: As it stands, billions of animals lead unimaginably horrible lives and die terrifying deaths each year, now nearly ten billion a year in the US alone.

de Waal: I think that, among intellectuals at least, there's a growing consensus that animals need to be treated better. We should eat less meat. My best experience with this was when I went to India, Tamil Nadu, which is completely vegetarian that part of India - completely vegetarian. For two weeks I didn't miss meat at all.

Feder: What would you like to see change in nonhuman animal research, or primate research specifically?

de Waal: Well, with chimpanzees the rules are changing. This has been in the making for the last twenty years. The moment is coming when we will say, 'We don't do invasive studies on them anymore'. I'm very pleased with that; I'm part of Chimp Haven, the place where most of these chimps will go in the end. Bonobos have never been used in invasive studies, but monkeys are massively used in many places. I think the same thing that happened with chimps is going to happen with monkeys.

I'm not saying that the primate research community should stop their studies, because there's still a need for a lot of this research, even though that may not be true twenty years from now if we transfer the whole human immune system to rodents. But I would like to see labs socially house their animals and treat them in a totally different way, and move away from most invasive research. I bet with some creativity they could. For example, the whole neuroscience of humans has moved from invasive procedures to fMRI imaging procedures in the scanner. This is going to happen, I think, with primate research as well. Attitudes need to change, but there's a lot of reluctance.

For example, people will say, 'For me to access my animals on a regular basis, I need to have them in single cages'. But I don't think that's true at all. I've been a primatologist long enough to know that you can train your animals. I had a capuchin lab where the monkeys lived in a group, and I would train them to come out for experiments. I never did any invasive stuff, but I could easily get them in individual situations if I needed to just by training. That's all very easy to do, but many biomedical scientists just sit in their labs; they don't even know where their primates are. They get their blood (or whatever) samples for analysis but they don't really know where they come from. They do not know the name or location of the monkey, or if it lives socially or not. If one studies something divorced from the animal, does one even care about where it comes from?

There's an ethical issue, obviously, but there's also a scientific issue here. Why are we studying isolation-housed monkeys on social and mental and physiological factors that are supposed to apply to humans who live socially? There's a mismatch between what we're testing in the monkeys and the humans that it's supposed to be for. 
Regarding the ethical question, I personally cannot understand how you would study animals, or any aspect of an animal, and not even know where they are, what they do, or how they live. But that's what the world has become. In my capuchin lab, which is now closed, we had an interesting situation: the monkeys lived in a group which was housed indoors and outdoors. We had windows in our office that looked out onto the monkeys. Every day we would see them and hear them. If there was a fight, we would immediately notice. We basically lived in our offices seeing our monkeys all the time.

Feder: And they could see you.

de Waal: They could see us and they got used to us that way. And they were curious if we did strange things in the lab. I feel that's how medical labs should be too - that you know your animals, you know where they are and you know what's going on with them. The least we can do for them in captivity is ensure a social life, which enriches their existence.

When you know the monkeys you work with, you're going to be hesitant to do certain things to them. In the same way that you would not do certain experiments on your dog at home, you would think twice before you do something to them. If it's strictly necessary to use primates, let's say to find an Ebola vaccine (something dramatically needed at this point), then you will use the minimum number of animals and treat them the best way possible. You will still do that research, but at least you've thought about it. What often happens now is that people don't even think about it. They say, 'Give me a hundred monkeys. Let's just do it'. That's how they react to things.

Feder: Anecdotal knowledge is another benefit of working closely with animals. What is the most interesting thing you've seen a nonhuman primate do at Yerkes?

de Waal: Well in my last book I described, for example, the last moment of a male who died and a female who took care of him. Those are the sort of things that strike me. They don't necessarily surprise me because I do believe that primates have empathy.

But they are very moving and interesting, and something you would never do an experiment on. Of course, people are always looking for the controlled experiment, but certain things, like big fights between males, you will never set up experimentally.

\section{Note}

1. http://www.brill.com/products/book/evolved-morality-biology-and-philosophy-humanconscience.

\section{Notes on contributor}

Helena Feder is Associate Professor of Literature and Environment at East Carolina University, where she directs the Great Books Program. She is the author of Ecocriticism and the Idea of Culture and various articles in Interdisciplinary Studies in Literature and Environment, Configurations, Green Letters, Women's Studies and the Journal of Ecocriticism. Helena has poetry and creative nonfiction in North American Review and ISLE. 